\title{
Identification of Microbial Products from Dibenzothiophene and Its Proposed Oxidation Pathway ${ }^{\dagger}$
}

\author{
Koki Kodama, Kazuyoshi Umehara, * Katsumi Shimizu, * Shigeru Nakatani, \\ Yasuji MinODA** and Koichi YAMADA** \\ Central Research Institute of Electric Power Industry, Abiko, Chiba Prefecture \\ * Research Laboratories, Fujisawa Pharmaceutical Co., Ltd., Higashiyodogawa-ku, Osaka \\ **Department of Agricultural Chemistry, Faculty of Agriculture, The University of Tokyo
}

Received June 2, 1972

\begin{abstract}
One of the microbial products produced from dibenzothiophene by Pseudomonas abikonensis or $P$. jianii was identified as a new substance, trans-4[2-(3-hydroxy)-thianaphthenyl]-2oxo-3-butenoic acid, and the other as its hemiacetal form. From the structures of the products, an oxidation pathway of dibenzothiophene was suggested. Moreover, the culture broth and the isolated products were examined for plant growth activities on rice plants.
\end{abstract}

In the previous reports ${ }^{1 \sim 3)}$ the authors indicated that dibenzothiophene utilizing bacteria were isolated from soils, and the activities of these bacteria were enhanced under the adequate culture conditions, and three of the microbial products from DBT were identified as 3-hydroxy-2-formyl-benzothiophene (product A), dibenzothiophene-5-oxide (product D) and 3-oxo-2[3'-hydroxy-thianaphthenyl-(2)methylene]-dihydrothianaphthene (product E).

This report deals with the structures of the remaining two substances (products $\mathbf{B}$ and $\mathbf{C}$ ) produced by the bacteria, and physiological effects of the broth and the isolated products, and then an assumed pathway of DBT oxidation by the bacteria.

\section{MATERIAIS AND METHODS}

Microorganisms and cultivation. In this studies, Pseudomonas jianii DDC 279 was used as a representative of 8 strains in DBT utilizing bacteria. The medium had the following composition $(\mathrm{g} / \mathrm{liter})$ : $\mathrm{MgCl}_{2} \cdot 6 \mathrm{H}_{2} \mathrm{O}, 0.2 ; \mathrm{KH}_{2} \mathrm{PO}_{4}, 1.4 ; \mathrm{Na}_{2} \mathrm{HPO}_{4} \cdot 12 \mathrm{H}_{2} \mathrm{O}$,

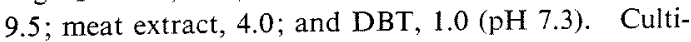
vation was carried out in the same procedures as described in the previous paper. ${ }^{31}$

Isolation procedures of products. Extraction procedure and silicagel column chromatography for

$\dagger$ Microbial Conversion of Petro-sulfur Compounds. Part IV.

Abbreviation used in this paper; DBT, dibenzothiophene. separation of the products from the culture broth were the same as reported in the previous paper. ${ }^{31}$

Analytical procedures. Ultraviolet spectra, infrared spectra and nuclear magnetic resonance spectra were obtained with following instruments: UV spectra, a Hitachi EPS-3; IR spectra, a Hitachi EPI-S2; NMR spectra, a VARIAN A60.

Color reaction with 2,4-dinitrophenylhydrazine, ferric chloride and bromine were employed for detection of functional groups as reported in the previous paper. ${ }^{31}$

Methylation of product. One hundred and seventyfive milligrams of product $\mathbf{B}$ were dissolved in $30 \mathrm{ml}$ of tetrahydrofuran, and $5 \mathrm{ml}$ of ether solution of diazomethane ( $c a .140 \mathrm{mg}$ ) was added gradually and agitated. After agitation, the reaction mixture was allowed to stand overnight in an ice box, and evaporated to remove the solvents, and the residue was extracted with ethyl acetate. The ethyl acetate solution was washed with $5 \%$ sodium hydrogen carbonate and then with water, dried on anhydrous sodium sulfate and evaporated to remove the ethyl acetate. After removal of solvent, the remaining residue was purified by crystallization from ethyl alcohol. Thus, methylated product $B$ was obtained as brown needle crystals.

Synthesis of product B. Product B was synthesized in the following procedures. One point two grams of 3-hydroxy-2-formyl-benzothiophene was added into $10 \mathrm{ml}$ of cooled $10 \%$ the sodium hydroxide solution containing $1 \mathrm{ml}$ of pyruvic acid and agitated for an hour in an ice bath, then $5 \mathrm{ml}$ of piperidine was dripped gradually for $30 \mathrm{~min}$. The reaction mixture was allowed to stand for 2 days at a room temperature, acidified with $2 \mathrm{~N}$ hydrochloric acid and extracted with 
ether. The ether extract was well washed with water and dried on anhydrous magnesium sulfate. After removal of the solvent, the synthesized substance was purified through a silica gel column with the procedure reported in the previous paper, ${ }^{31}$

Enzymatic reaction. Crude enzyme was prepared by the following method. Two grams of wet packed cells cultured for 6 days were dehydrated and defatted with cold acetone, suspended in $40 \mathrm{ml}$ of phosphate buffer consisting of potassium phosphate monobasic $0.14 \%$, sodium phosphate $0.95 \%$ and magnesium chloride $0.02 \%$ at $\mathrm{pH} 7.3$. The cell suspension was treated with an ultrasonic oscillator at $19.5 \mathrm{kc} / \mathrm{sec}$ for 15 min. The supernatant was obtained by centrifugation at $10,000 \times g$ for $20 \mathrm{~min}$.

Enzymatic reactions of products $\mathrm{B}$ and $\mathrm{C}$ were conducted as follows. One milliliter of the supernatant was mixed in $4 \mathrm{ml}$ of substrate solution consisting of $1 \mu \mathrm{mol}$ of product $\mathrm{B}$ or $\mathrm{C}$ dissolved in $5 \mathrm{ml}$ of the phosphate buffer, respectively. Reaction was carried out at $30^{\circ} \mathrm{C}$ under shaking condition. After the reaction, amounts of product $\mathbf{B}(485 \mathrm{~m} \mu)$, product $\mathrm{C}(440 \mathrm{~m} \mu)$ and product $\mathrm{A}(400 \mathrm{~m} \mu)$ were measured spectrophotometrically at each wave length as shown in the above parentheses.

Tests for physiological effects. Auxin or antiauxin assay was examined by the lamina joint test, ${ }^{4}$ in which the angle between lamina and sheath of rice plant was measured after the treatment. Gibberellin assay was examined by the seedling test, ${ }^{5}$ in which the plant height and the root length were measured after the treatment of 7 days.

Antibiotic effects of the products were assayed with the pulp disc method. ${ }^{61}$ The substances were used at the concentration of $0.1 \%$.

\section{RESULTS AND DISCUSSION}

\section{Analysis and identification of product $B$}

Product B, a red substance, was found in a trace amount in the culture broth. It had a value of $R f 0.75$ on paper chromatogram (EtOH- $\mathrm{NH}_{4} \mathrm{OH}-\mathrm{H}_{2} \mathrm{O}, 20: 1: 15$ ) and an absorption peak at $475 \mathrm{~m} \mu$ in phosphate buffer at $\mathrm{pH} 7.3, \mathrm{mp} 269 \sim 273^{\circ} \mathrm{C}$ (decomp). Anal. Found: C, 57.81; H, 3.46; S, 12.95. Calcd. for $\mathrm{C}_{12} \mathrm{H}_{8} \mathrm{O}_{4} \mathrm{~S}: \mathrm{C}, 58.06 ; \mathrm{H}, 3.25 ; \mathrm{S}, 12.92 \%$. This substance was positive to the alcoholic ferric chloride test, the 2,4-dinitrophenylhydrazine test and the bromine test. From the results of the color reactions, the presence of phenolic hydroxyl group and carbonyl

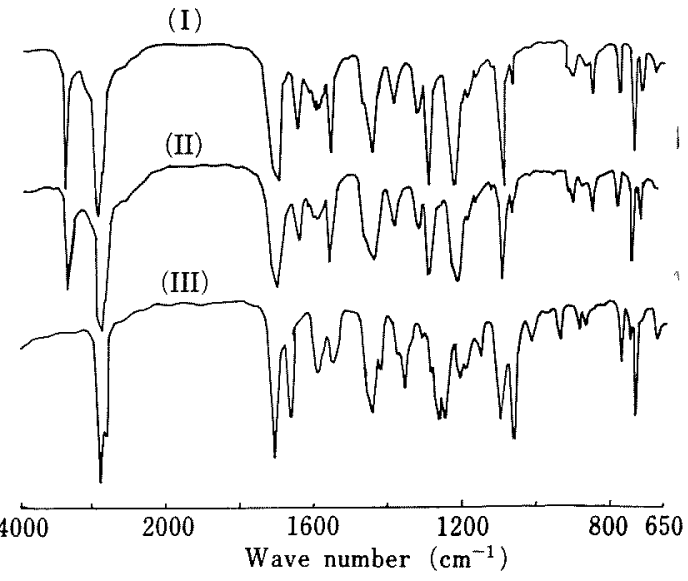

FIG. 1. IR Spectra of Product B (I), Synthetic trans-4[2-(3-Hydroxy)-thianaphthenyl]-2-oxo-3 - butenoic Acid (II) and Methylated Product B (III) in Nujol.

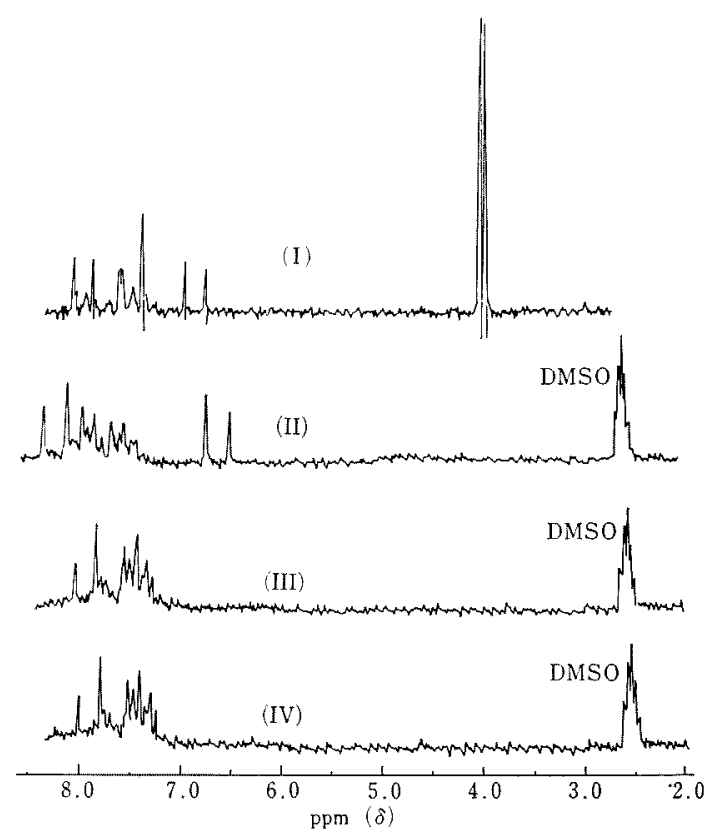

FIG. 2. NMR Spectra of Products.

(I): Methylated Product $\mathrm{B}$ in $\mathrm{CDCl}_{3}, 60 \mathrm{Mc}$.

(II): Product $\mathrm{B}$ in $\mathrm{d}_{6}$-DMSO, $60 \mathrm{Mc}$.

(III): Product $\mathrm{C}$ in $\mathrm{d}_{6}-\mathrm{DMSO}, 60 \mathrm{Mc}$.

(IV): Product $\mathrm{C}^{\prime}$ in $\mathrm{d}_{6}-\mathrm{DMSO}, 60 \mathrm{Mc}$.

group were presumed. IR $\nu_{\mathrm{max}}^{\text {Nujol }} \mathrm{cm}^{-1}: 3350$, 1700, 1640, 1600, 1500, 1430, 730 (Fig. 1-I). NMR (DMSO): $\delta 8.10(1 \mathrm{H}, \mathrm{d}, J=14 \mathrm{cps,}$ -CHCHCO-), $6.50(1 \mathrm{H}, \mathrm{d}, J=14 \mathrm{cps},-\mathrm{CH}-$ CHCO-), $6.33 \sim 7.89$ (4H, m) (Fig. 2-II).

Methylated product $\mathrm{B}$ was found to have 
following characteristics: positive to the 2,4dinitrophenylhydrazine test and the bromine test, negative to the alcoholic ferric chloride test; brown needle crystals; $\mathrm{mp} 155 \sim 156^{\circ} \mathrm{C}$. Anal. Found: C, 60.96; H, 4.26; S, 11.17 . Calcd. for $\mathrm{C}_{14} \mathrm{H}_{12} \mathrm{O}_{4} \mathrm{~S} ; \mathrm{C}, 60.86 ; \mathrm{H}, 4.38 ; \mathrm{S}$, $11.61 \%$ The IR spectrum of methylated product $\mathrm{B}$ showed the absence of phenolic hydroxyl group at $3350 \mathrm{~cm}^{-1}$ (Fig. 1-III). NMR $\left(\mathrm{CDCl}_{3}\right): \delta 7.80(1 \mathrm{H}, \mathrm{d}, J=12 \mathrm{cps}$, $-\mathrm{CHCHCO}-), 6.75(1 \mathrm{H}, \mathrm{d}, J=12 \mathrm{cps},-\mathrm{CH}-$ CHCO- $), 3.93\left(3 \mathrm{H}, \mathrm{s},-\mathrm{OCH}_{3}\right), 3.90(3 \mathrm{H}, \mathrm{s}$, $-{ }_{\mathrm{COOCH}}$ ) (Fig. 2-I).

The NMR coupling constants $(J=14 \mathrm{cps})$ show trans form of this product comparing with those of product $\mathrm{C}(J=13 \mathrm{cps})$ as mentioned later. Therefore, product $\mathrm{B}(\mathrm{I})$ and its methyl ester (II) were considered to have following structures, respectively.
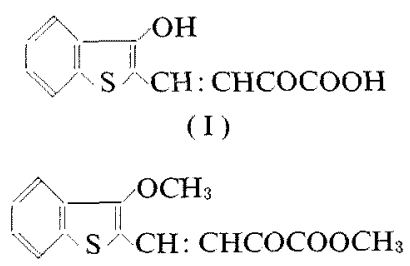

(II)

Product B had the IR spectrum identical with that of the synthesized trans-4[2-(3-hydroxy)-thianaphthenyl]-2-oxo-3-butenoic acid as shown in Fig. 1. Therefore, product B was identified as the above compound.

\section{Analysis of product $C$}

Product $\mathrm{C}$, orange needle crystals, had a value of $R f 0.77$ on paper chromatogram (EtOH-NH $4{ }_{4} \mathrm{OH}-\mathrm{H}_{2} \mathrm{O}, 20: 1: 15$ ), and an absorption peak at $437 \mathrm{~m} \mu$ in the phosphate buffer, mp $189 \sim 191^{\circ} \mathrm{C}$ (decomp). Anal. Found: C, 57.01; H, 3.20; S, 12.72. Calcd. for $\mathrm{C}_{12} \mathrm{H}_{8} \mathrm{O}_{4} \mathrm{~S}: \mathrm{C}, 58.06 ; \mathrm{H}, 3.25 ; \mathrm{S}, 12.92 \%$. This substance was positive to the alcoholic ferric chloride test, the 2,4-dinitrophenylhydrazine test. IR $\nu_{\mathrm{m} u x}^{\mathrm{Nu} j 01} \mathrm{~cm}^{-1}: 3200,1690$, 1640, 1620, 1560, 1440, 710 (Fig. 3-1). Broad spectra at the vicinity of $3200 \mathrm{~cm}^{-1}$ suggest that the hydroxyl group is not phenolic, but alcoholic one. NMR (DMSO): ô $7.9(1 \mathrm{H}$,
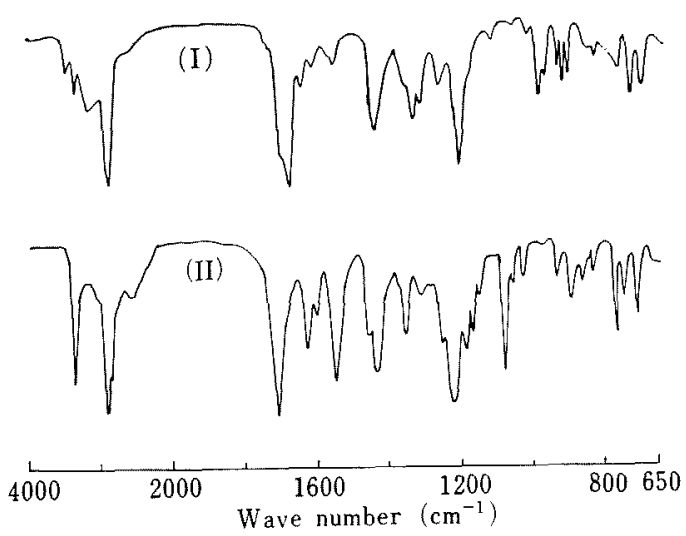

FIg. 3. IR Spectra of Product C (I) and Product $C^{\prime}$ (II) in Nujol.

d, $J=13 \mathrm{cps}), 7.4(1 \mathrm{H}, \mathrm{d}, J=13 \mathrm{cps})$ (Fig. 2-III). Thus, product $C$ had an empirical formula identical with that of product $\mathrm{B}$ and the functional groups similar to those of it without phenolic hydroxyl group, but had a lower melting point, $\lambda_{\max }$ at a shorter wave length and smaller coupling constants of NMR spectrum than those of product B. From the above reasons, product $C$ was presumed to be hemiacetal form (III) of product $B$.

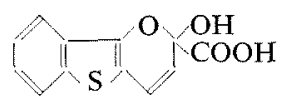

(III)

\section{Properties and structure of product $C$}

Product $\mathrm{C}$ changed to a reddish substance similar to product $B$ when it was left a silica gel column with chloroform under dried condition at a room temperature for a week. The substance was purified with ether extraction and by chromatograph on a silica gel column. The purified substance was designated as product $\mathrm{C}^{\prime}$. The melting point and absorption spectrum (Fig. 4) were identical with those of product $C$. IR $\nu_{\max }^{\mathrm{Najo1}} \mathrm{cm}^{-1}: 3350,1710,1630$, 1600, 1550, 1440, 720 (Fig. 3-II). NMR (DMSO): $\delta 7.9(1 \mathrm{H}, \mathrm{d}, J=13 \mathrm{cps}), 7.4(1 \mathrm{H}, \mathrm{d}$, $J=13 \mathrm{cps}$ ) (Fig. 2-IV). Thus, the functional groups of product $C^{\prime}$ should be identical with those of product $\mathrm{B}$, but the coupling constants of two olefinic protons in the side chain, the $\lambda_{\max }$ of absorption spectrum and the melting 


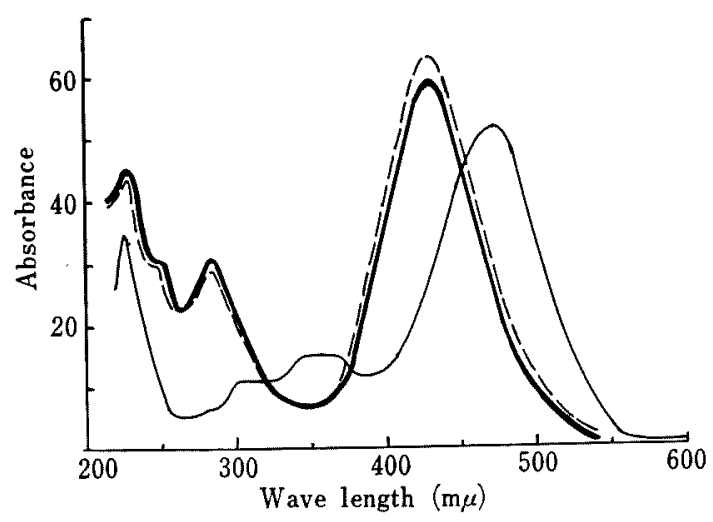

FIG. 4. Absorption Spectra of Products.

Product $\mathrm{B},-$ Product $\mathrm{C},---$ Product $\mathrm{C}^{\prime}$ Solvent: pH 7.0, $0.05 \mathrm{M}$ Phosphate buffer.

point were identical with those of product $C$. Product C' (IV) was presumed to be cis form of product $\mathrm{B}$ on the basis of the smaller coupling constants, $\lambda_{\mathrm{max}}$ of absorption at a shorter wave length and a lower melting point than those of product $\mathrm{B}$.<smiles></smiles>

(IV)

\section{Enzymatic degradation of product}

As Fig. 5 shows, when product B was incubated with the enzyme solution, the amount of product B decreased and concomitantly product $A$ appeared. In the case of product $\mathrm{C}$, the amount of product $\mathrm{C}$ did not change, and no increase in the amount of product $A$ was found. The results of the enzymatic reaction indicated that the enzyme converted product $B$ to product $A$, not converting product $\mathrm{C}$ to Product $\mathrm{A}$.

\section{Proposed pathway of DBT metabolism}

As reported in the previous paper, DBT was oxidatively converted to the five substances, i.e., dibenzothiophene-5-oxide, 3hydroxy-2-formyl-benzothiophene, 3-oxo[3'- hydroxy - thianaphthenyl - (2) - methylene) dihydrothianaphthene, products $B$ and $C$. In this study, products $\mathrm{B}$ and $\mathrm{C}$ were identified as trans and hemiacetal form of 4[2-(3-

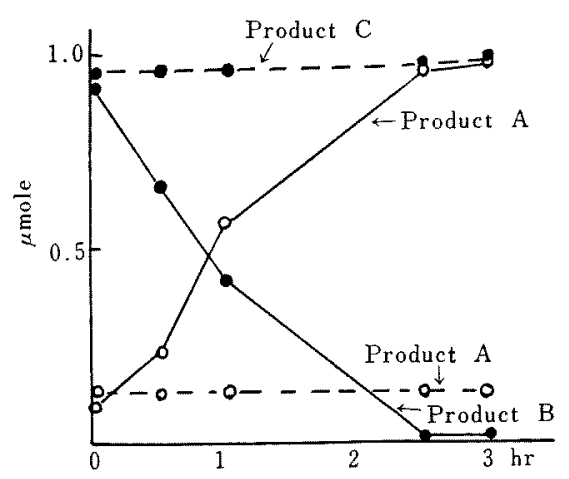

FIG. 5. Conversion of Product $B$ and Product $C$ by Crude Enzyme.

- incubated with Product B

hydroxy) - thianaphthenyl] - 2 - oxo - 3 - butenoic acid, respectively. And, cis form of product B was easily produced from product $\mathrm{C}$ by artificial procedures. As judged from the structures of the products and the results of the enzymatic reaction, DBT was assumed to be metabolized oxidatively to 3-hydroxy-2formyl-benzothiophene by the DBT utilizing bacteria according to the pathway shown in Fig. 6, which is analogous to the pathway of naphthalene decomposition by Pseudomonas, ${ }^{7 \sim 9)}$ though the cleavage of the thiophene ring was not found in this experiment. On the assumption that cis-4[2-(3-hydroxy)-thianaphthenyl]-2-oxo-3-butenoic acid was rapidly converted to the trans form by the action of cis-trans isomerase, the cis form was considered to be an immediate ring-fission product of DBT. The hemiacetal form was found in the broth, but it was not converted to 3-hydroxy-2-formyl-benzothiophene by the crude enzyme. The hemiacetal form is presumably not a member of the main pathway.

Since 3 - hydroxy - 2 - formyl-benzothiophene showed the greatest yield of the five products and being rapidly produced from trans-4[2(3-hydroxy) - thianaphthenyl]-2-oxo-3-butenoic acid, DBT was mainly metabolized through cis - 4[2-(3-hydroxy)-thianaphthenyl]-2-oxo-3butenoic acid and its trans form to 3-hydroxy2-formyl-benzothiophene.

Dibenzothiophene-5-oxide was an interest- 


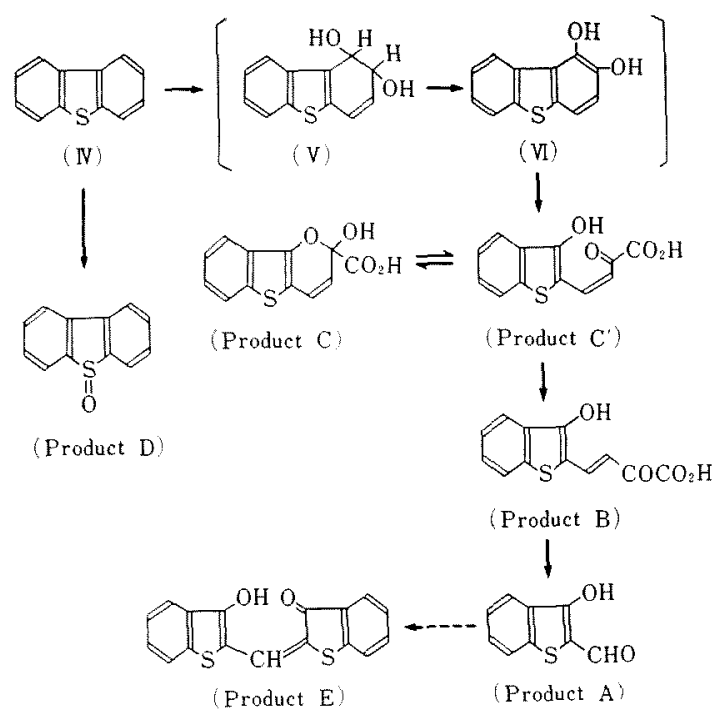

Fig. 6. Proposed Pathway of Dibenzothiophene Metabolism by Pseudomonas abikonensis or $P$. jianii.

(IV): Dibenzothiophene, (V): D-trans-1,2-Dihydro1,2-dihydroxydibenzothiophene, (VI): 1,2-Dihydroxydibenzothiophene. (Product A): 3-Hydroxy-2-formylbenzothiophene. (Product B): trans-4[2-(3-Hydroxy)thianaphthenyl]-2-oxo-3-butenoic acid. (Product $\mathrm{C}$ ): Hemiacetal form of Product $C^{\prime}$. (Product $C^{\prime}$ ): cis4[2-(3-Hydroxy) - thianaphthenyl] - 2-oxo-3 - butenoic acid. (Product D): Dibenzothiophene-5-oxide. (Product E): 3-Oxo-[3'-hydroxy-thianaphthenyl-(2)methylenel-dihydrothianaphthene.

ing substance, which was not presented by enzymatic evidence. The isolation procedures converted 3-hydroxy-2-formyl-benzothiophene to 3 - oxo-2[3'-hydroxy - thianaphthenyl-(2)methylene]-dihydrothianaphthene.

Physiological effects of the broth and the products

Antiauxin and gibberellin like activities were found in the cultured broth. As Table I shows, the angle of lamina joint was reduced to $50 \%$ against the control when the samples were treated with the broth diluted 5 times plus $10 \mathrm{ppm}$ of indole-3-acetic acid. The presence of an antiauxin substance was shown by the reduction of the angle degree, and a $50 \%$ reduction was equivalent to the presence of $50 \mathrm{ppm}$ of 2,3,5-triiodobenzoic acid. The culture broth diluted 5 times caused the elongation of the height of plants and the
Table I. Effects of the Culture Broth on the Growth of Rice Plants

control: 100

\begin{tabular}{|c|c|c|c|c|c|c|c|}
\hline \multirow{2}{*}{\multicolumn{4}{|c|}{ Method }} & \multicolumn{4}{|c|}{ Concentration } \\
\hline & & & & \multirow[t]{2}{*}{$1 / 5$} & \multicolumn{2}{|c|}{$1 / 10$} & $1 / 20$ \\
\hline \multicolumn{7}{|c|}{ Lamina joint test } & \\
\hline \multicolumn{4}{|c|}{ Broth only } & 79 & \multicolumn{2}{|c|}{96} & 93 \\
\hline \multicolumn{4}{|c|}{ Plus IAA 10 ppm } & 50 & \multicolumn{2}{|c|}{70} & 70 \\
\hline \multicolumn{8}{|c|}{ Seedling test } \\
\hline \multirow{2}{*}{\multicolumn{4}{|c|}{$\begin{array}{l}\text { Plant height } \\
\text { Length of } 2 \text { nd leaf sheath }\end{array}$}} & 150 & \multicolumn{2}{|c|}{120} & 90 \\
\hline & & & & 134 & \multicolumn{2}{|c|}{132} & 87 \\
\hline \multicolumn{8}{|c|}{$\begin{array}{l}\text { Table II. Effects of the Products on the } \\
\text { Root Growth of Rice Plant Seedlings } \\
\text { control: } 100 ; 5 \mathrm{~cm}\end{array}$} \\
\hline \multirow{2}{*}{\multicolumn{2}{|c|}{ Substance }} & \multicolumn{6}{|c|}{ Concentration (ppm) } \\
\hline & & 100 & 50 & 25 & 10 & 5 & 2 \\
\hline \multirow[t]{5}{*}{ Product } & A & 90 & 132 & 146 & 145 & 122 & 110 \\
\hline & $\mathrm{B}$ & 96 & 88 & 111 & 119 & 103 & 103 \\
\hline & $\mathrm{C}$ & 74 & 103 & 113 & 123 & 101 & 104 \\
\hline & $\mathrm{D}$ & 58 & 62 & 80 & 81 & 86 & 93 \\
\hline & $\mathrm{E}$ & 109 & 109 & 103 & 104 & 103 & 96 \\
\hline
\end{tabular}

length of the second leaf sheath of rice seedlings. Therefore, the presence of a gibberellin like substance was presumed to be at the concentration of $0.1 \mathrm{ppm}$ of gibberellin A.

Among the separated products, as shown in Table II, product A was found to have gibberellin like effect; elongation of the root length of rice seedlings was observed with $10 \sim 50 \mathrm{ppm}$. Products D and E were found to have antibiotic effects. The growth of Xanthomonas citri which induces canker in citrus fruits was inhibited by product $D$, and that of Piricularia orizae which induces blast in rice plants was inhibited by product $E$.

\section{REFERENCES}

1) K. Yamada, Y. Minoda, K. Kodama, S. Nakatani and T. Akasaki, Agr. Biol. Chem., 32, 840 (1968).

2) S. Nakatani, T. Akasaki, K. Kodama, Y. Minoda and K. Yamada, ibid., 32, 1205 (1968).

3) K. Kodama, S. Nakatani, K. Umehara, K. Shimizu, Y. Minoda and K. Yamada, ibid., 34, 1320 (1970).

4) E. Maeda, Physiol. Planta., 13, 204, 214 (1960). 
5) Y. Murakami, Bot. Mag. Tokyo, 81, 33 (1968).

6) H. Kojima, Y. Matsuya, H. Ozawa, M. Konno and T. Uemura, Nippon Nogeikagaku Kaishi, 32, 33 (1958).

7) J. I. Davis and W. C. Evans, Biochem. J., 91,
251 (1964).

8) H. N. Fernley and W. C. Evans, Nature, 4632, 373 (1958).

9) M. H. Rogoff and I. Wender, J. Bacteriol., 74, 108 (1957). 